\title{
TRENDS IN THE PREVALENCE OF FRAILTY IN JAPAN: A META-ANALYSIS FROM THE ILSA-J
}

\author{
H. MAKIZAKO ${ }^{1}$, Y. NISHITA ${ }^{2}$, S. JEONG $^{3}$, R. OTSUKA ${ }^{4}$, H. SHIMADA ${ }^{5}$, K. IIJIMA $^{6}$, S. OBUCHI ${ }^{7}$, \\ H. $\mathrm{KIM}^{8}$, A. KITAMURA ${ }^{9}$, Y. OHARA ${ }^{8}$, S. AWATA ${ }^{8}$, N. YOSHIMURA ${ }^{10}$, M. YAMADA $^{11}$, \\ K. TOBA ${ }^{12}$, T. SUZUKI ${ }^{13}$
}

\begin{abstract}
1. Department of Physical Therapy, Faculty of Medicine, School of Health Sciences, Kagoshima University, Kagoshima, Japan; 2. Department of Epidemiology, National Center for Geriatrics and Gerontology, Obu, Japan; 3. Department Community Welfare, Niimi University, Niimi, Japan; 4. Section of NILS-LSA, National Center for Geriatrics and Gerontology, Obu, Japan; 5. Department of Preventive Gerontology, National Center for Geriatrics and Gerontology, Obu, Japan; 6. Institute of Gerontology, The University of Tokyo, Bunkyo-ku, Japan; 7. Research Team for Human Care, Tokyo Metropolitan Institute of Gerontology, Itabashi-ku, Japan; 8. Research Team for Promoting Independence and Mental Health, Tokyo Metropolitan Institute of Gerontology, Itabashi-ku, Japan; 9. Research Team for Social Participation and Community Health, Tokyo Metropolitan Institute of Gerontology, Itabashi-ku, Japan; 10. Department of Joint Disease Research, 22nd Century Medical and Research Center, The University of Tokyo, Bunkyo-ku, Japan; 11. Graduate School of Comprehensive

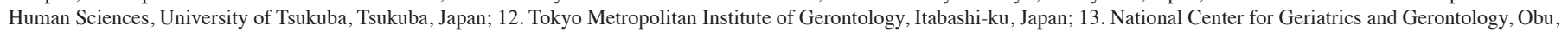
Japan \& Institute of Gerontology, J.F. Oberlin University, Machida, Japan.

Corresponding author: Hyuma Makizako, Department of Physical Therapy, Faculty of Medicine, School of Health Sciences, Kagoshima University, Kagoshima, Japan, makizako@health.nop.kagoshima-u.ac.jp
\end{abstract}

\begin{abstract}
Objective: To examine whether age-specific prevalence of frailty in Japan changed between 2012 and 2017. Design: This study performed meta-analyses of data collected from 2012 to 2017 using the Integrated Longitudinal Studies on Aging in Japan (ILSA-J), a collection of representative Japanese cohort studies. Setting: The ILSA-J studies were conducted on community-living older adults. Participants: ILSA-J studies were considered eligible for analysis if they assessed physical frailty status and presence of frailty in the sample. Seven studies were analyzed for $2012( \pm 1$ year; $\mathrm{n}=10312)$ and eight studies were analyzed for $2017( \pm 1$ year; $\mathrm{n}$ = 7010). Five studies were analyzed for both 2012 and 2017. Measurements: The study assessed the prevalence of frailty and frailty status according to 5 criteria: slowness, weakness, low activity, exhaustion, and weight loss. Results: The overall prevalence of physical frailty was $7.0 \%$ in 2012 and $5.3 \%$ in 2017 . The prevalence of frailty, especially in people 70 years and older, tended to decrease in 2017 compared to 2012. Slight decreases were found in the prevalence of frailty subitems including weight loss, slowness, exhaustion, and low activity between 2012 and 2017, but change in the prevalence of weakness was weaker than other components. Conclusions: The prevalence of physical frailty decreased from 2012 to 2017 . There are age- and gender-related variations in the decrease of each component of frailty.
\end{abstract}

Key words: Frailty, aging, cohort study, older.

\section{Introduction}

Frailty is defined as a clinically recognizable state of increased vulnerability in older adults resulting from ageassociated declines in physiologic reserves and function across multiple organ systems (1). Although it is recognized as a multidimensional construct, comprising psychological and social conditions and symptoms in addition to physical, the physical frailty phenotype is well defined and its impact on adverse health outcomes such as disability, hospitalization, and death has been examined in many prior studies (2-5). Clinical practice guidelines based on the current evidence base provide recommendations for identifying and managing frailty in older adults (6). Reducing the risk and prevalence of frailty may play an important role in extending healthy life expectancy in the aged population.

The most common components used to assess physical frailty are the frailty phenotype proposed by Fried et al. using data from the Cardiovascular Health Study (CHS) (2). Based on the Fried criteria, a wide prevalence of frailty has been Received June 16, 2020

Accepted for publication November 2, 2020 reported among community-dwelling people aged 65 years and older, ranging from $4 \%$ to $27 \%(7,8)$. In Japan, with a rapidly increasing aging population, the overall prevalence of frailty was $7.4 \%$, with a similar prevalence in men $(7.6 \%)$ and women $(8.1 \%)(9)$. These prevalence rates increased with advancing age $(1.9 \%, 3.8 \%, 10.0 \%, 20.4 \%$, and $35.1 \%$ for people aged 65 to 69,70 to 74,75 to 79,80 to 84 , and 85 or older, respectively) (9).

In the past several decades, both life and health expectancy have increased in many countries. In Japan, the average life expectancy was 81.3 years for men and 87.3 years for women in 2018, according to data from the Ministry of Health. There may be improvement in physical health status among older adults based on increased life and health expectancy. Although previous studies indicated the prevalence of frailty in a large cohort or meta-analysis, no studies focused on trends in the prevalence of frailty and assessment years.

This study performed meta-analyses using data from the National Center for Geriatrics and Gerontology's Integrated Longitudinal Studies on Aging in Japan (ILSA-J), a collection 


\section{TRENDS IN THE PREVALENCE OF FRAILTY IN JAPAN}

Table1

Characteristics of the cohort studies included in the meta-analysis

\begin{tabular}{|c|c|c|c|c|c|c|c|c|c|c|c|c|c|c|}
\hline \multirow[t]{3}{*}{ Cohort } & \multicolumn{7}{|c|}{2012} & \multicolumn{7}{|c|}{2017} \\
\hline & \multirow[t]{2}{*}{$\mathbf{N}$ of subjects } & \multirow[t]{2}{*}{ Gender (Women \%) } & \multicolumn{5}{|c|}{ Age group (n) } & \multirow[t]{2}{*}{$\mathrm{N}$ of subjects } & \multirow[t]{2}{*}{ Gender (Women \%) } & \multicolumn{5}{|c|}{ Age group (n) } \\
\hline & & & $65-69$ & $70-74$ & $75-79$ & $80-84$ & 85-89 & & & $65-69$ & $70-74$ & $75-79$ & $80-84$ & 85-89 \\
\hline A & 4779 & $51.1 \%$ & 1898 & 1479 & 866 & 412 & 124 & 1249 & $49.2 \%$ & 0 & 0 & 667 & 433 & 149 \\
\hline B & 874 & $48.6 \%$ & 239 & 234 & 208 & 136 & 57 & N/A & N/A & N/A & N/A & N/A & N/A & N/A \\
\hline $\mathrm{C}$ & 545 & $100.0 \%$ & 0 & 0 & 111 & 333 & 101 & 1021 & $100.0 \%$ & 389 & 317 & 271 & 44 & 0 \\
\hline $\mathrm{D}$ & 564 & $55.0 \%$ & 162 & 151 & 135 & 87 & 29 & 590 & $59.6 \%$ & 127 & 178 & 156 & 94 & 35 \\
\hline $\mathrm{E}$ & 791 & $57.0 \%$ & 212 & 245 & 207 & 99 & 28 & 831 & $57.2 \%$ & 335 & 157 & 192 & 99 & 48 \\
\hline $\mathrm{F}$ & N/A & N/A & N/A & N/A & N/A & N/A & N/A & 1196 & $59.5 \%$ & 0 & 376 & 457 & 282 & 81 \\
\hline $\mathrm{G}$ & 809 & $67.6 \%$ & 206 & 218 & 188 & 139 & 58 & N/A & N/A & N/A & N/A & N/A & N/A & N/A \\
\hline $\mathrm{H}$ & 1950 & $50.4 \%$ & 631 & 625 & 432 & 205 & 57 & 927 & $47.2 \%$ & 45 & 371 & 294 & 158 & 59 \\
\hline I & N/A & N/A & N/A & N/A & N/A & N/A & N/A & 287 & $55.1 \%$ & 86 & 81 & 49 & 51 & 20 \\
\hline $\mathrm{J}$ & N/A & N/A & N/A & N/A & N/A & N/A & N/A & 909 & $63.7 \%$ & 210 & 264 & 196 & 160 & 79 \\
\hline
\end{tabular}

of 13 longitudinal cohort studies on aging in Japan involving community-dwelling older adults, to test whether the agespecific prevalence of frailty changed in Japan between 2012 and 2017.

\section{Methods}

\section{Data Sources}

This study performed meta-analyses using ILSA-J data on frailty. The ILSA-J included a total of 13 longitudinal cohort studies conducted throughout Japan (Table 1). Studies were considered eligible for inclusion in the present analysis if they assessed physical frailty status and prevalence of frailty in the sample using the Fried criteria (2) (e.g., slowness, weakness, exhaustion, low activity, and weight loss). Of the 13 cohort studies, 7 (total $\mathrm{n}=10312 ; 4611$ men and 5701 women) were analyzed for 2012 ( \pm 1 year), and 8 (total $n=7010 ; 2662$ men and 4348 women) were analyzed for 2017 ( \pm 1 year). Finally, only 10 of the 13 cohort studies in the ILSA-J project were included in this meta-analysis, because 3 cohort studies did not provide data on frailty status in 2012 and 2017.

\section{Main Outcome Measures and Operational Definition of} Frailty

The main outcome measures in this study were the prevalence of frailty status and the five frailty sub-items (\%). This study determined physical frailty status according to the 5 criteria of physical frailty suggested by the Japanese version of the CHS (J-CHS) $(10,11)$ and a slightly revised criterion: weight loss, slowness, weakness, exhaustion, and low activity. Participants whose responses did not correspond to any of these target criteria were considered to be robust; those who responded positively for 1 or 2 criteria were considered prefrail; and those with 3 or more positive criteria responses were considered frail.

Although all the cohort studies included in the current meta-analysis used the same 5 criteria to assess frailty status, there were differences in the subcriteria (Appendix table $1)$. The 5 criteria defining physical frailty were assessed as follows. Weight loss was identified by a response of "yes" to the question (12), "Have you lost $2 \mathrm{~kg}$ or more in the past 6 months?" Slowness was identified by a normal walking speed of $<1.0 \mathrm{~m} / \mathrm{s}(10)$. Weakness was identified according to grip strength of the subject's dominant hand: $<26 \mathrm{~kg}$ for men and $<18 \mathrm{~kg}$ for women (13). Exhaustion was identified by a response of "yes" to the question (12), "In the last 2 weeks, have you felt tired for no reason?" Low activity was identified by a response of "no" to both the following questions (10): "Do you engage in moderate levels of physical exercise or sports aimed at health?" and "Do you engage in low levels of physical exercise aimed at health?"

\section{Data Collection}

All ILSA-J cohort studies were approved by the ethics committee of the relevant university or institute. Among the 13 total cohort studies, those that assessed frailty provided data on the prevalence of frailty status (frailty, pre-frailty, and robust) and the 5 frailty subitems for meta-analyses. Thus, no author of the present study could access participants' individual data.

\section{Statistical Analysis}

A two-step approach was used in the current study. First, we obtained the frailty prevalence in each cohort study separately, then, we calculated the combined prevalence using meta-analysis. The prevalence rates of frailty and prefrailty for the years 2012 and 2017 were calculated by age group and gender. The 5 frailty items were also included to calculate prevalence. The present meta-analysis used a twostep approach. First, Cochran's Q test was used to assess the presence of heterogeneity across cohorts, indicated by $\mathrm{p}<0.05$, and I 2 statistic values of $25 \%, 50 \%$, and $75 \%$ indicated low, moderate, and high degrees of heterogeneity, respectively (14). 


\section{THE JOURNAL OF FRAILTY \& AGING}

Table 2

Prevalence of physical frailty by age group

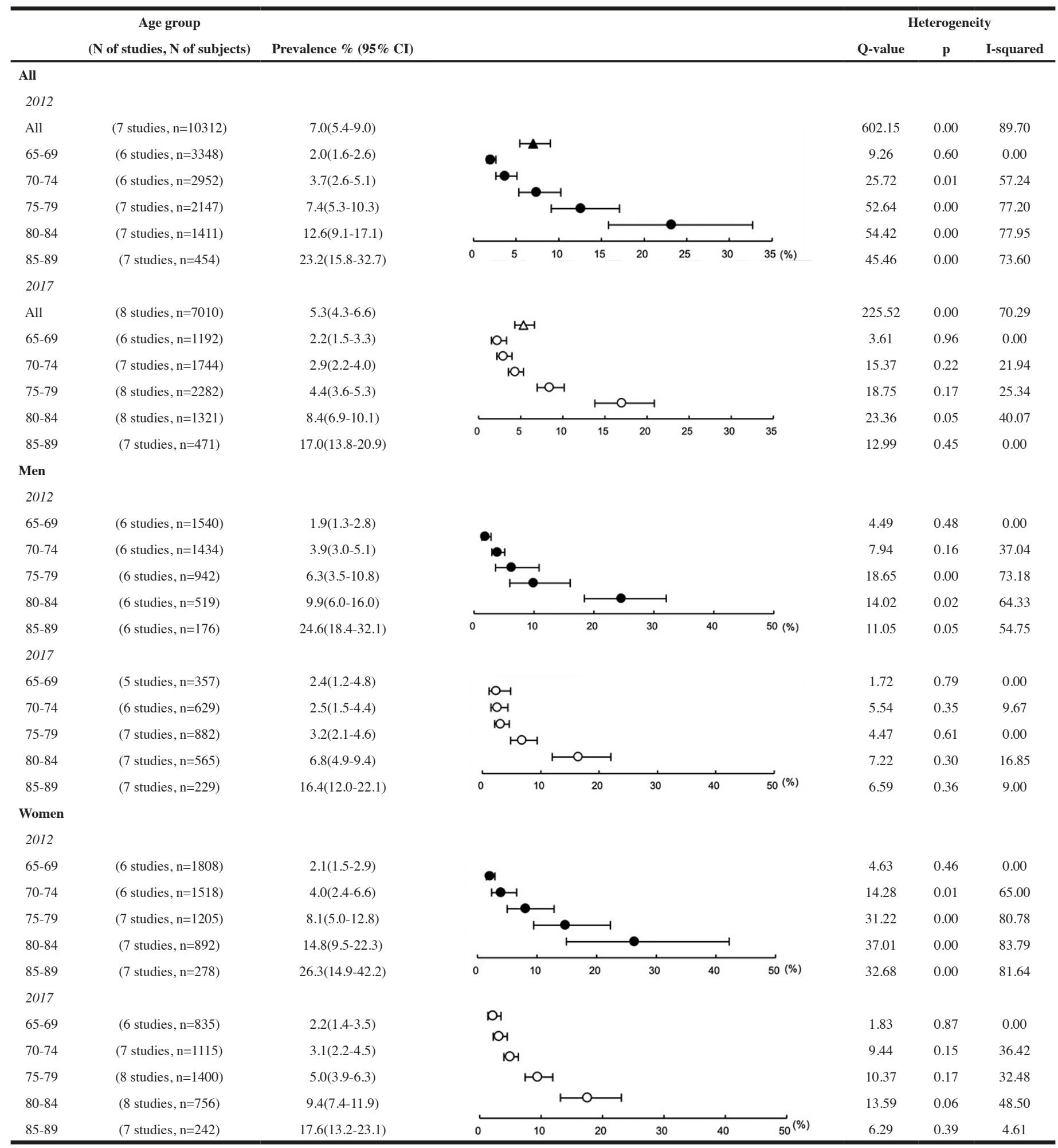




\section{TRENDS IN THE PREVALENCE OF FRAILTY IN JAPAN}

Then, prevalence and 95\% confidence intervals (CIs) were calculated for frailty and pre-frailty using a random-effects model if heterogeneity was present $(\mathrm{p}<0.05)$ and a fixed-effects model if heterogeneity was absent based on Cochran's Q test (9). In addition, we performed a sensitivity analysis restricting the meta-analysis to surveys performed at both time-points, 2012 and 2017. Statistical analyses were completed using Comprehensive Meta-Analysis software (Version 3; Biostat, Englewood, NJ, USA).

\section{Results}

Table 2 presents the data on the presence of heterogeneity across cohorts and the prevalence of physical frailty among each age group in 2012 and 2017. There was a slight decrease $(1.7 \%)$ in overall prevalence of physical frailty between 2012 and 2017. The overall prevalence of physical frailty was 7.0\% (95\% CI 5.4-9.0\%) in 2012 and 5.3\% (95\% CI 4.3-6.6\%) in 2017. The sensitivity analysis restricted to surveys with data at both time-points (2012 and 2017) provided similar results to the main analysis (Appendix table 2). Greater decreases in the prevalence of frailty were found in adults aged 75 years and older. Specifically, in 2012, the prevalence of frailty was $7.4 \%$ in the $75-79$ age group, $12.6 \%$ in the $80-84$ group, and $23.2 \%$ in the 85-89 group. In 2017, a $3.0 \%$ decrease was found in the $75-79$ age group, a $4.2 \%$ decrease in the $80-84$ group, and a $6.2 \%$ decrease in the 85-89 group.

Among men, frailty prevalence increased with advancing age in both 2012 and 2017. In 2012, prevalence was $6.3 \%$ in the $75-79$ age group, $9.9 \%$ in the $80-84$ group, and $24.6 \%$ in the 85-89 group ; in 2017, a decrease of $3.1 \%$ was found in the $75-79$ age group (prevalence of $3.2 \%$ ), $3.1 \%$ in the $80-84$ group (prevalence of 6.8\%), and $8.2 \%$ in the $85-89$ group (prevalence of $16.4 \%)$.

Similar trends were observed in women. The prevalence of frailty in 2012 was $8.1 \%$ in the $75-79$ age group, $14.8 \%$ in the 80-84 group, and $26.3 \%$ in the $85-89$ group. In 2017, a decrease of $3.1 \%$ was found in the 75-79 age group (prevalence of $5.0 \%$ ), $5.4 \%$ in the 80-84 group (prevalence of 9.4\%), and $8.7 \%$ in the 85-89 group (prevalence of 17.6\%).

The gender-stratified prevalence of physical frailty subitems is shown in Tables 3 and 4. Regardless of gender, slight decreases (less than 5\%) in the subitems were found between 2012 and 2017 among young old groups (ages 65-69 and 70-74), with the exception of low activity in men aged 65-69 and women aged 70-74. Differing trends between men and women were found among old groups (ages 75-79, 80-84, and 85-89). In men, subitems with greater decreases (more than 5\%) included exhaustion, which decreased $6.0 \%$ in the $75-79$ age group, $5.2 \%$ in the $80-84$ group, and $8.9 \%$ in the $85-89$ group; slowness, which decreased $7.7 \%$ in the $85-59$ group; and low activity, which decreased $7.2 \%$ in the $85-89$ group).

Compared with men, women were found to have decreased prevalence in many components. In the $75-79$ age group, all components expect for weakness decreased (weight loss, 9.7\%; slowness, 5.8\%; exhaustion, 7.3\%; low activity, 6.4\%). All components decreased in the 80-84 and 85-89 groups (weight loss, $7.5 \%$ and $8.1 \%$, respectively; slowness, $12.1 \%$ and $16.6 \%$; weakness, $6.1 \%$ and $5.5 \%$; exhaustion, $9.3 \%$ and $5.8 \%$; low activity, $5.4 \%$ and $5.9 \%)$.

\section{Discussion}

This study performed meta-analyses using data from ILSA-J cohort studies and showed that the prevalence of frailty tended to decrease in 2017 compared to 2012, especially in adults 75 years and older. The sensitivity analysis confirmed the main findings and indicates that this increases the robustness of the findings.

A recent systematic review of articles published in 28 countries estimated the global incidence of frailty among community-dwelling adults (15). Among robust individuals who survived a median follow-up of 3.0 years, $13.6 \%$ became frail, with a pooled incidence rate of 43.4 cases per 1000 person-years (15); incidence rates varied by diagnostic criteria and country income level. Previous systematic review and meta-analysis studies have also suggested variation in the prevalence of frailty based on diagnostic criteria (16), country income level (17), and residential environment (18, 9). Additionally, the prevalence of frailty among communitydwelling older adults has been reported to differ based on race $(9,19)$. Therefore, the influences of those characteristics should be considered when discussing the prevalence of frailty and prevention strategies.

Most systematic review and meta-analysis studies that examine the prevalence of frailty include articles published after 2000. Worldwide, there were 901 million people aged 60 years or over in 2015 , an increase of $48 \%$ over the global total of 607 million older people in 2000 (20). The global number of people aged 60 years or over increased by $68 \%$ in urban areas, compared to $25 \%$ in rural areas, from 2000 to 2015 (20). In Japan, approximately $12 \%$ of the population was 65 years or older in 1990, about the same as the total in the USA in 1990 (21). By 2010, the 65 and older population in Japan doubled, rising from 15 million to 29 million and comprising $23 \%$ of the total population, the highest proportion in the world (21). The percentage rose to over $28 \%$ in 2019 . Although the number of older people in Japan is increasing rapidly, their latent capabilities and background factors can be changed. Health-related measures among Japanese community-dwelling older adults from 2007 to 2017 indicate that a phenomenon of "rejuvenation" is occurring among the new generation of older Japanese adults (22). In the United States, dementia declined significantly between 2000 and 2012, and one associated factor was an increase in educational attainment (23). Thus, better change in older adults' latent capabilities and background factors may lead to a decrease in the prevalence of frailty. 
THE JOURNAL OF FRAILTY \& AGING

Table 3

Prevalence of physical frailty components (Men)

\begin{tabular}{|c|c|c|c|c|c|c|c|c|}
\hline \multirow[t]{3}{*}{ Age group } & \multicolumn{4}{|c|}{2012} & \multicolumn{4}{|c|}{2017} \\
\hline & \multirow[t]{2}{*}{ Prevalence \% (95\% CI) } & \multicolumn{3}{|c|}{ Heterogeneity } & \multirow[t]{2}{*}{ Prevalence \% (95\% CI) } & \multicolumn{3}{|c|}{ Heterogeneity } \\
\hline & & Q-value & $\mathbf{p}$ & I-squared & & Q-value & $\mathbf{p}$ & I-squared \\
\hline \multicolumn{9}{|l|}{ Weight loss } \\
\hline $65-69$ & $16.2(14.4-18.2)$ & 7.79 & 0.17 & 35.83 & $16.8(13.2-21.1)$ & 2.19 & 0.70 & 0.00 \\
\hline $70-74$ & $14.1(10.1-19.4)$ & 22.00 & 0.00 & 77.27 & $13.0(10.5-15.9)$ & 7.94 & 0.16 & 37.05 \\
\hline $75-79$ & $13.7(11.7-16.1)$ & 3.71 & 0.59 & 0.00 & $10.0(8.2-12.3)$ & 5.99 & 0.42 & 0.00 \\
\hline $80-84$ & $15.1(12.1-18.5)$ & 8.77 & 0.12 & 42.98 & $10.5(8.0-13.6)$ & 5.87 & 0.44 & 0.00 \\
\hline $85-89$ & $13.7(9.2-19.8)$ & 2.70 & 0.75 & 0.00 & $14.5(10.4-19.9)$ & 5.01 & 0.54 & 0.00 \\
\hline \multicolumn{9}{|l|}{ Slowness } \\
\hline $65-69$ & $4.2(1.7-10.1)$ & 35.72 & 0.00 & 86.00 & $3.3(1.9-5.9)$ & 0.87 & 0.93 & 0.00 \\
\hline $70-74$ & $6.9(2.8-15.8)$ & 66.53 & 0.00 & 92.48 & $5.6(3.0-10.2)$ & 13.45 & 0.02 & 62.82 \\
\hline $75-79$ & $10.1(4.8-20.1)$ & 53.46 & 0.00 & 90.65 & $8.9(5.4-14.2)$ & 21.56 & 0.00 & 72.17 \\
\hline $80-84$ & $20.7(10.7-36.4)$ & 53.22 & 0.00 & 90.60 & $16.8(11.3-24.1)$ & 18.66 & 0.00 & 67.84 \\
\hline $85-89$ & $38.5(19.0-62.6)$ & 33.39 & 0.00 & 85.03 & $30.8(24.9-37.4)$ & 11.30 & 0.08 & 46.88 \\
\hline \multicolumn{9}{|l|}{ Weakness } \\
\hline $65-69$ & $2.0(0.8-4.9)$ & 15.51 & 0.01 & 67.75 & $4.6(2.8-7.4)$ & 1.55 & 0.82 & 0.00 \\
\hline $70-74$ & $6.8(5.5-8.2)$ & 10.46 & 0.06 & 52.20 & $6.9(4.0-11.8)$ & 14.16 & 0.01 & 64.68 \\
\hline $75-79$ & $11.6(7.7-17.1)$ & 19.27 & 0.00 & 74.06 & $10.4(7.5-14.4)$ & 13.28 & 0.04 & 54.81 \\
\hline $80-84$ & $20.8(14.3-29.2)$ & 18.95 & 0.00 & 73.61 & $19.4(16.3-22.9)$ & 10.33 & 0.11 & 41.92 \\
\hline $85-89$ & $32.9(20.4-48.4)$ & 16.88 & 0.00 & 70.38 & $39.5(27.6-52.8)$ & 17.70 & 0.01 & 66.10 \\
\hline \multicolumn{9}{|l|}{ Exhaustion } \\
\hline $65-69$ & $12.2(6.8-20.8)$ & 55.48 & 0.00 & 90.99 & $12.0(7.1-19.6)$ & 9.80 & 0.04 & 59.19 \\
\hline $70-74$ & $13.8(7.0-25.4)$ & 86.52 & 0.00 & 94.22 & $13.4(10.9-16.3)$ & 3.31 & 0.65 & 0.00 \\
\hline $75-79$ & $19.0(12.5-27.8)$ & 36.45 & 0.00 & 86.28 & $13.0(8.8-18.8)$ & 22.03 & 0.00 & 72.76 \\
\hline $80-84$ & $23.5(16.1-32.9)$ & 22.28 & 0.00 & 77.56 & $18.3(11.3-28.1)$ & 31.69 & 0.00 & 81.07 \\
\hline $85-89$ & $29.8(18.8-43.8)$ & 14.41 & 0.01 & 65.30 & $20.9(15.9-26.9)$ & 8.84 & 0.18 & 32.13 \\
\hline \multicolumn{9}{|l|}{ Low activity } \\
\hline $65-69$ & $20.0(13.3-29.1)$ & 50.15 & 0.00 & 90.03 & $26.0(21.6-30.8)$ & 6.04 & 0.20 & 33.82 \\
\hline $70-74$ & $17.8(11.9-25.9)$ & 42.51 & 0.00 & 88.24 & $15.6(12.9-18.7)$ & 9.69 & 0.08 & 48.42 \\
\hline $75-79$ & $20.8(13.5-30.7)$ & 42.08 & 0.00 & 88.12 & $16.0(13.7-18.6)$ & 8.49 & 0.20 & 29.31 \\
\hline $80-84$ & 21.1(12.3-33.9) & 39.61 & 0.00 & 87.38 & $16.9(14.0-20.3)$ & 8.04 & 0.23 & 25.40 \\
\hline $85-89$ & $26.8(14.9-43.4)$ & 17.18 & 0.00 & 70.90 & $19.6(14.9-25.3)$ & 2.63 & 0.85 & 0.00 \\
\hline
\end{tabular}

Several important factors, such as comorbidities, low socioeconomic position, poor diet, and sedentary lifestyle, increase the risks of frailty (24). Some of these are modifiable. Therefore, it may be possible to reduce the prevalence of frailty by controlling or improving risk factors. Although this study's meta-analyses had a relatively short observational term of 5 years, decreasing trends in the prevalence of frailty may become clearer based on long-term observation.
Among 5 components of frailty, weakness and slowness may have greater impacts on increased risk of disability $(11,25)$. In this study, there was a decreasing trend in the prevalence of almost all items, however there was less change in the prevalence of weakness compared with other items. No change or a slight increase in the prevalence of weakness was observed in men in all age groups, whereas for women, only a decrease in the 80 years and older group was observed. 
TRENDS IN THE PREVALENCE OF FRAILTY IN JAPAN

Table 4

Prevalence of physical frailty components (Women)

\begin{tabular}{|c|c|c|c|c|c|c|c|c|}
\hline \multirow[t]{3}{*}{ Age group } & \multicolumn{4}{|c|}{2012} & \multicolumn{4}{|c|}{2017} \\
\hline & \multirow[t]{2}{*}{ Prevalence \% (95\% CI) } & \multicolumn{3}{|c|}{ Heterogeneity } & \multirow[t]{2}{*}{ Prevalence \% (95\% CI) } & \multicolumn{3}{|c|}{ Heterogeneity } \\
\hline & & Q-value & $\mathbf{p}$ & I-squared & & Q-value & $\mathbf{p}$ & I-squared \\
\hline \multicolumn{9}{|l|}{ Weight loss } \\
\hline $65-69$ & $13.5(10.0-17.9)$ & 21.38 & 0.00 & 76.61 & $12.1(10.0-14.5)$ & 2.59 & 0.76 & 0.00 \\
\hline $70-74$ & 13.1(11.4-14.9) & 5.40 & 0.37 & 7.38 & $9.5(6.2-14.2)$ & 26.26 & 0.00 & 77.15 \\
\hline $75-79$ & $17.3(15.2-19.6)$ & 7.51 & 0.28 & 20.11 & 7.6(5.1-11.2) & 27.10 & 0.00 & 74.17 \\
\hline $80-84$ & $18.0(15.6-20.7)$ & 6.34 & 0.39 & 5.41 & $10.5(7.1-15.2)$ & 18.00 & 0.01 & 61.11 \\
\hline $85-89$ & $22.1(17.5-27.5)$ & 5.28 & 0.51 & 0.00 & $14.0(10.0-19.2)$ & 3.47 & 0.75 & 0.00 \\
\hline \multicolumn{9}{|l|}{ Slowness } \\
\hline $65-69$ & $4.1(2.3-7.3)$ & 20.69 & 0.00 & 75.84 & $4.7(3.4-6.5)$ & 6.29 & 0.28 & 20.49 \\
\hline $70-74$ & $6.0(2.9-12.2)$ & 51.15 & 0.00 & 90.22 & $4.2(2.5-7.0)$ & 16.95 & 0.01 & 64.60 \\
\hline $75-79$ & $16.5(9.2-28.0)$ & 101.01 & 0.00 & 94.06 & $10.7(9.2-12.5)$ & 8.26 & 0.31 & 15.29 \\
\hline $80-84$ & $32.0(19.9-47.2)$ & 98.14 & 0.00 & 93.89 & $19.9(15.5-25.2)$ & 16.60 & 0.02 & 57.84 \\
\hline $85-89$ & $54.3(36.9-70.7)$ & 37.70 & 0.00 & 84.08 & $37.7(31.7-44.1)$ & 9.48 & 0.15 & 36.71 \\
\hline \multicolumn{9}{|l|}{ Weakness } \\
\hline $65-69$ & $7.0(3.8-12.3)$ & 38.77 & 0.00 & 87.10 & $9.3(7.5-11.5)$ & 5.41 & 0.37 & 7.59 \\
\hline $70-74$ & $10.3(6.9-15.1)$ & 26.01 & 0.00 & 80.78 & $11.7(8.2-16.4)$ & 24.26 & 0.00 & 75.27 \\
\hline $75-79$ & $19.1(12.0-29.1)$ & 74.73 & 0.00 & 91.97 & $19.9(16.4-23.8)$ & 19.00 & 0.01 & 63.17 \\
\hline $80-84$ & $33.1(26.7-40.0)$ & 23.01 & 0.00 & 73.92 & $27.0(21.0-33.9)$ & 24.12 & 0.00 & 70.98 \\
\hline $85-89$ & $55.1(49.1-60.9)$ & 9.43 & 0.15 & 36.40 & $49.6(43.2-56.0)$ & 8.67 & 0.19 & 30.83 \\
\hline \multicolumn{9}{|l|}{ Exhaustion } \\
\hline $65-69$ & $15.0(9.9-22.0)$ & 47.08 & 0.00 & 89.38 & $13.9(9.8-19.5)$ & 14.50 & 0.01 & 65.51 \\
\hline $70-74$ & $20.6(14.6-28.3)$ & 43.34 & 0.00 & 88.46 & $15.9(12.7-19.6)$ & 13.87 & 0.03 & 56.74 \\
\hline $75-79$ & $26.7(19.6-35.2)$ & 49.42 & 0.00 & 87.86 & $19.4(15.3-24.3)$ & 28.13 & 0.00 & 75.11 \\
\hline $80-84$ & $29.6(20.9-40.1)$ & 49.44 & 0.00 & 87.86 & $20.3(14.5-27.5)$ & 29.17 & 0.00 & 76.01 \\
\hline $85-89$ & $31.3(19.7-45.9)$ & 27.55 & 0.00 & 78.22 & $25.5(16.4-37.5)$ & 17.80 & 0.01 & 66.30 \\
\hline \multicolumn{9}{|l|}{ Low activity } \\
\hline $65-69$ & $16.8(12.1-22.8)$ & 31.84 & 0.00 & 84.30 & $17.9(15.4-20.7)$ & 6.01 & 0.30 & 16.84 \\
\hline $70-74$ & $18.0(13.9-22.9)$ & 20.55 & 0.00 & 75.67 & $12.4(10.6-14.4)$ & 2.54 & 0.86 & 0.00 \\
\hline $75-79$ & $18.3(13.6-24.0)$ & 29.01 & 0.00 & 79.32 & $11.9(8.9-15.8)$ & 23.49 & 0.00 & 70.20 \\
\hline $80-84$ & $21.0(14.3-29.8)$ & 41.50 & 0.00 & 85.54 & $15.6(13.2-18.4)$ & 5.64 & 0.58 & 0.00 \\
\hline $85-89$ & $27.4(16.8-41.4)$ & 25.60 & 0.00 & 76.56 & $21.5(16.6-27.3)$ & 7.36 & 0.29 & 18.46 \\
\hline
\end{tabular}

This study found significant differences in frailty prevalence between men and women. Older women, especially in the oldold population (aged 75 years and over), were found to have decreased prevalence in almost all frailty items. Recently, the ILSA-J reported differences between the years 2007 ( \pm 2 years) and 2017 ( \pm 2 years) in several indices (e.g., body composition, walking speed, and grip strength) that are related to the health and functioning of older adults (22). Better health status and a slower decline in most of the health-related measures were observed in 2017 compared with a decade ago. Japanese older adults living in the community have been consistently increasing their walking speed over the past 25 years, and the improvement in walking speed is especially striking in women $(26,27)$. In a previous study that analyzed IADL performance in 17,680 older adults with dependency in basic ADL, the men were found to have 3 times higher prevalence of poor performance of IADL compared with the women (28). Older adult women may reduce age-related decline in functional level 


\section{THE JOURNAL OF FRAILTY \& AGING}

by increasing or maintaining the multidimensional aspects of their lives, such as social and leisure time activities. In addition, our data showed higher study participation rates in women than in men for both 2012 and 2017. These findings may indicate that women have more interest in their health compared with men. Increased interest in personal health may prevent or delay the progression of frailty.

Consistent "female disadvantage" in physical performance among older adults has been demonstrated (29). One previous study with 4683 Japanese nondisabled community-dwelling older adults demonstrated increasing significant gender differences in one-legged stance performance and gait speed with age. In contrast, gender differences significantly decreased in hand-grip strength with increasing age (30). In other words, strength may be more affected by advancing age in older adult men than in older adult women. Thus, preventing or delaying the progression of weakness with age may be difficult in men. Weakness was determined according to grip strength of the subject's dominant hand, with cutoff values of $26 \mathrm{~kg}$ for men and $18 \mathrm{~kg}$ for women. Although the average values of grip strength may decrease slightly in new generation of Japanese older adults (22), the changes may not reach sufficient levels, indicating that this component is less susceptible to generation changes than the others.

Several limitations of the present study should be noted. First, the meta-analyses in the present study used crosssectional data from 7 cohort studies in 2012 ( \pm 1 year) and 8 cohort studies in 2017 ( \pm 1 year). Therefore, the study design was not longitudinal, following the same individuals and cohorts. Second, the current study used data from 2012 and 2017, analyzing the trends in prevalence over a period of 5 years. This may be too short to fully examine trends of change. Third, the number of participants varied widely by age group, especially participants in the 85 and older group, which had a relatively small sample size (fewer than 200 men in 2012). Finally, assessment protocols were dependent on each cohort study, not unified across all cohorts. We believe that the cohort studies included in the current metaanalysis had high data quality, but not all of the studies were designed using probabilistic samples. For instance, recruitment methods (e.g., random sampling, direct mail to all citizen, and volunteers) varied. In addition, more knowledge on the prevalence of the risk factors for frailty and those components, such as comorbidities, nutritional status, and cognitive function will support the phenomenon of decreasing frailty in the new generation of Japanese older adults.

Although this study examines a relatively short period of time (5 years), it has several strengths. First, it is, to our knowledge, the first study to describe trends in the prevalence of frailty. Second, the prevalence of frailty and subitems were assessed through a meta-analysis of 10 Japanese cohort studies, which provided data from 287 to 4779 older adults. Third, frailty status was assessed not only by questionnaires but also by objective measures such as grip strength and walking speed; therefore, are results may reflect functional status.

In conclusion, the current meta-analyses suggested that the prevalence of frailty has shown a decreasing trend in the new generation of Japanese older adults, especially in adults aged 75 years and older. This finding may indicate physical rejuvenation in older adults. Progression of this trend may improve health expectancy and shorten the gap between life expectancy and health expectancy. Future studies with more long-term followup period and a larger sample will be needed to clarify the trends in the prevalence of frailty among community-dwelling older adults.

Acknowledgement: This work was funded by the National Center for Geriatrics and Gerontology (Choujyu 29-42). We are grateful to all the participants for their valuable contribution to this study. The authors thank Dr. Katsunori Kondo of the National Center for Geriatrics and Gerontology \& Chiba University, Dr. Yoshinori Fujiwara of the Tokyo Metropolitan Institute of Gerontology, and Dr. Shuichiro Watanabe of J.F. Oberlin University who are members of the ILSA-J project for their contributions in study progression. We also thank to Dr. Takehiko Doi of the National Center for Geriatrics and Gerontology, Dr. Tomoki Tanaka of the Institute of Gerontology, The University of Tokyo, Dr. Hisashi Kawai, Dr. Yu Nofuji, Dr. Takumi Abe and Dr. Susumu Ogawa of the Tokyo Metropolitan Institute of Gerontology, Dr. Yu Taniguchi of National Institute for Environmental Studies, and Dr. Yutaka Watanabe of the Faculty of Dental Medicine, Hokkaido University for their helpful supporting data sharing process and Ms. Shiho Fujii of the National Center for Geriatrics and Gerontology for her help in preparing the tables.

Conflicts of Interest: None declared.

Ethics Statement: This study was conducted in compliance with the current laws of Japan.

Open Access: This article is distributed under the terms of the Creative Commons Attribution 4.0 International License (http://creativecommons.org/licenses/by/4.0/), which permits use, duplication, adaptation, distribution and reproduction in any medium or format, as long as you give appropriate credit to the original author(s) and the source, provide a link to the Creative Commons license and indicate if changes were made.

\section{References}

1. Chen X, Mao G, Leng SX. Frailty syndrome: an overview. Clin Interv Aging 2014;9:433-41. doi: 10.2147/CIA.S45300

2. Fried LP, Tangen CM, Walston J, Newman AB, Hirsch C, Gottdiener J, et al Frailty in older adults: evidence for a phenotype. J Gerontol A Biol Sci Med Sci. 2001;56(3):M146-56. doi: 10.1093/gerona/56.3.m146

3. Ensrud KE, Ewing SK, Taylor BC, Fink HA, Cawthon PM, Stone KL, et al. Comparison of 2 frailty indexes for prediction of falls, disability, fractures, and death in older women. Arch Intern Med 2008;168(4):382-9. doi: 10.1001/ archinternmed.2007.113

4. Clegg A, Young J, Iliffe S, Rikkert MO, Rockwood K. Frailty in elderly people. Lancet. 2013;381(9868):752-62. doi: 10.1016/S0140-6736(12)62167-9

5. Pereira AA, Borim FSA, Aprahamian I, Neri AL. Comparison of two models of frailty for the prediction of mortality in Brazilian community-dwelling older adults: The FIBRA study. J Nutr Health Aging 2019;23(10):1004-10. doi: 10.1007/s12603-019 1264-0

6. Dent E, Morley JE, Cruz-Jentoft AJ, Woodhouse L, Rodriguez-Manas L, Fried LP, et al. Physical frailty: ICFSR international clinical practice guidelines for identification and management. J Nutr Health Aging 2019;23(9):771-87. doi: 10.1007/s12603-019 $1273-\mathrm{z}$ 


\section{TRENDS IN THE PREVALENCE OF FRAILTY IN JAPAN}

7. Collard RM, Boter H, Schoevers RA, Oude Voshaar RC. Prevalence of frailty in community-dwelling older persons: A systematic review. J Am Geriatr Soc. 2012;60(8):1487-92. doi: 10.1111/j.1532-5415.2012.04054.x

8. Choi J, Ahn A, Kim S, Won CW. Global prevalence of physical frailty by Fried's criteria in community-dwelling elderly with national population-based surveys. J Am Med Dir Assoc 2015;16(7):548-50. doi: 10.1016/j.jamda.2015.02.004

9. Kojima G, Iliffe S, Taniguchi Y, Shimada H, Rakugi H, Walters Prevalence of frailty in Japan: A systematic review and meta-analysis. J Epidemiol 2017;27(8):347-53. doi: 10.1016/j.je.2016.09.008

10. Shimada H, Makizako H, Doi T, Yoshida D, Tsutsumimoto K, Anan Y, et al. Combined prevalence of frailty and mild cognitive impairment in a population of elderly Japanese people. J Am Med Dir Assoc 2013;14(7):518-24. doi: 10.1016/j.jamda.2013.03.010

11. Makizako H, Shimada H, Doi T, Tsutsumimoto K, Suzuki T. Impact of physical frailty on disability in community-dwelling older adults: A prospective cohort study. BMJ open 2015;5(9):e008462. doi: 10.1136/bmjopen-2015-008462

12. Fukutomi E, Okumiya K, Wada T, Sakamoto R, Ishimoto Y, Kimura Y, et al. Relationships between each category of 25-item frailty risk assessment (Kihon Checklist) and newly certified older adults under Long-Term Care Insurance: A 24-month follow-up study in a rural community in Japan. Geriatr Gerontol Int 2015;15(7):864-71. doi: 10.1111/ggi.12360

13. Chen LK, Liu LK, Woo J, Assantachai P, Auyeung TW, Bahyah KS, et al. Sarcopenia in Asia: Consensus report of the Asian Working Group for Sarcopenia. J Am Med Dir Assoc 2014;15(2):95-101. doi: 10.1016/j.jamda.2013.11.025

14. Higgins JP, Thompson SG, Deeks JJ, Altman DG. Measuring inconsistency in metaanalyses. BMJ 2003;327(7414):557-60. doi: 10.1136/bmj.327.7414.557

15. Ofori-Asenso R, Chin KL, Mazidi M, Zomer E, Ilomaki J, Zullo AR, et al. Global incidence of frailty and prefrailty among community-dwelling older adults: A systematic review and meta-analysis. JAMA Netw Open 2019;2(8):e198398. doi: 10.1001/jamanetworkopen.2019.8398

16. He B, Ma Y, Wang C, Jiang M, Geng C, Chang X, et al. Prevalence and risk factors for frailty among community-dwelling older people in China: A systematic review and meta-analysis. J Nutr Health Aging 2019;23(5):442-50. doi: 10.1007/s12603-019$1179-9$

17. Siriwardhana DD, Hardoon S, Rait G, Weerasinghe MC, Walters KR. Prevalence of frailty and prefrailty among community-dwelling older adults in low-income and middle-income countries: A systematic review and meta-analysis. BMJ open 2018;8(3):e018195. doi: 10.1136/bmjopen-2017-018195

18. Kojima G. Prevalence of frailty in nursing homes: A systematic review and metaanalysis. J Am Med Dir Assoc 2015;16(11):940-5. doi: 10.1016/j.jamda.2015.06.025
19. Da Mata FA, Pereira PP, Andrade KR, Figueiredo AC, Silva MT, Pereira MG Prevalence of frailty in Latin America and the Caribbean: A systematic review and meta-analysis. PLoS One 2016;11(8):e0160019. doi: 10.1371/journal.pone.0160019

20. United Nations. Department of Economic and Social Affaris, Population Dynamics. World Population Prospects. http://esa.un.org/unpd/wpp/DataQuery/ Accessed 18 December 2019.

21. Tamiya N, Noguchi H, Nishi A, Reich MR, Ikegami N, Hashimoto H, et al. Population ageing and wellbeing: Lessons from Japan's long-term care insurance policy. Lancet 2011;378(9797):1183-92. doi: 10.1016/S0140-6736(11)61176-8

22. Suzuki T, Nishita Y, Jeong S, Shimada H, Otsuka R, Kondo K, et al. Are Japanese older adults rejuvenating? Changes in health-related measures among older community dwellers in the last decade. Rejuvenation Res 2020; in press. doi: 10.1089/ rej.2019.2291

23. Langa KM, Larson EB, Crimmins EM, Faul JD, Levine DA, Kabeto MU, et al. A comparison of the prevalence of dementia in the United States in 2000 and 2012 JAMA Intern Med 2017;177(1):51-58. doi: 10.1001/jamainternmed.2016.6807

24. Hoogendijk EO, Afilalo J, Ensrud KE, Kowal P, Onder G, Fried LP. Frailty: implications for clinical practice and public health. Lancet 2019;394(10206):1365-75. doi: 10.1016/S0140-6736(19)31786-6

25. Shimada H, Makizako H, Doi T, Tsutsumimoto K, Suzuki T. Incidence of disability in frail older persons with or without slow walking speed. J Am Med Dir Assoc 2015;16(8):690-6. doi: 10.1016/j.jamda.2015.03.019

26. Suzuki T, Kwon J. Health status of older adults living in the community in Japan: Recent changes and significance in the super-aged society. Geriatr Gerontol Int 2018;18(5):667-677. doi: 10.1111/ggi.1326627. Suzuki T. Health status of older adults living in the community in Japan: Recent changes and significance in the super-aged society. Geriatr Gerontol Int. 2018 May;18(5):667-77.

28. Tomioka K, Kurumatani N, Hosoi H. Age and gender differences in the association between social participation and instrumental activities of daily living among community-dwelling elderly. BMC Geriatr 2017;17(1):99. doi: 10.1186/s12877-0170491-7

29. Sialino LD, Schaap LA, van Oostrom SH, Nooyens ACJ, Picavet HSJ, Twisk JWR, et al. Sex differences in physical performance by age, educational level, ethnic groups and birth cohort: The Longitudinal Aging Study Amsterdam. PLoS One 2019;14(12):e0226342. doi: 10.1371/journal.pone.0226342

30. Seino S, Shinkai S, Fujiwara Y, Obuchi S, Yoshida H, Hirano H, et al. Reference values and age and sex differences in physical performance measures for communitydwelling older Japanese: A pooled analysis of six cohort studies. PLoS One 2014;9(6):e99487. doi: 10.1371/journal.pone.0099487 